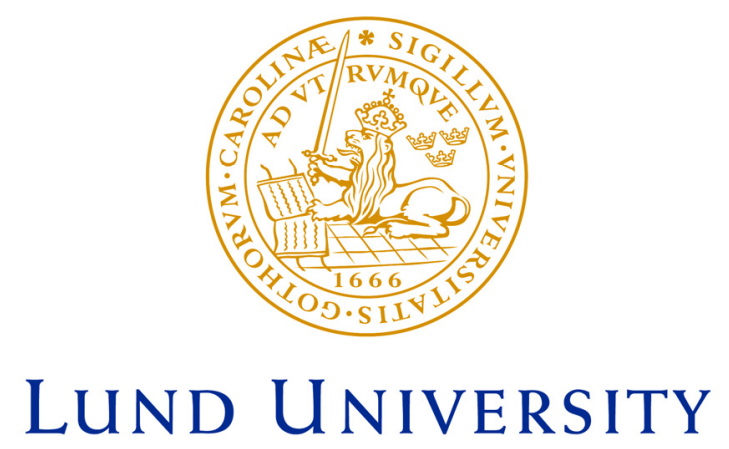

Faculty of Medicine

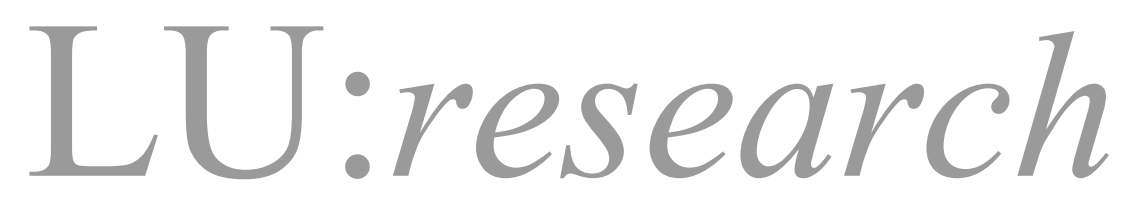

Institutional Repository of Lund University

This is an author produced version of a paper published in Gastroenterology. This paper has been peer-reviewed but does not include the final publisher proof-corrections or journal pagination.

Citation for the published paper:

Ohlsson, Bodil and Veress, Béla and Janciauskiene, Sabina and Montgomery, Agneta and Haglund, Monica and Wallmark, Anders.

"Chronic intestinal pseudo-obstruction due to buserelininduced formation of anti-GnRH antibodies" Gastroenterology, 2007, Vol: 132, Issue: 1, pp.45-51.

http://dx.doi.org/ 10.1053/j.gastro.2006.10.036

Access to the published version may require journal subscription.

Published with permission from: Elsevier 


\section{Chronic intestinal pseudo-obstruction due to buserelin- induced formation of anti-GnRH antibodies}

Short title- Pseudo-obstruction and buserelin

Bodil Ohlsson ${ }^{1}$, Béla Veress ${ }^{2}$, Sabina Janciauskiene ${ }^{1}$, Agneta Montgomery ${ }^{3}$, Monica Haglund $^{2}$ and Anders Wallmark ${ }^{1}$

Department of Clinical Sciences, Gastroenterology Division ${ }^{1}$, Department of Laboratory Medicine, Pathology Division ${ }^{2}$ and Department of Surgery ${ }^{3}$, Malmö University Hospital, Lund University, 20502 Malmö, Sweden.

Grant support- We thank Dr. A. Widell for providing the patient serum samples and Camilla Orbjörn for technical assistence. The work was supported by grants from the Lundström Foundation and the Swedish Research Council. Dr. B. Ohlsson was supported by a personal unrestricted grant from the Novo Nordic Foundation.

Abbreviations- CIPO, chronic intestinal pseudo-obstruction, ICCs, interstitial cells of Cajal, $\mathrm{GnRH}$, gonadotropin releasing hormone, LH-RH, luteinization hormone-releasing hormone, IVF, in-vitro fertilization,

Correspondence to:

Assoc Prof. Anders Wallmark (MD, PhD)

Department of Clinical Sciences

Malmö University Hospital

Entrance 35, S-205 02 Malmö, Sweden

Phone: +4640331000 (operator)

Fax : +4640337041

E-mail : anders.wallmark@sbbs.se 


\section{Abstract}

Background/Aim. A 30 year-old woman, treated with buserelin, an analogue of gonadotropin -releasing hormone (GnRH) (also called luteinizing hormone-releasing hormone, LH-RH), developed chronic intestinal pseudo-obstruction (CIPO). The sudden onset of this disease in a previously healthy woman perplexed us. CIPO refers to a gastrointestinal disorder that can have a variety of causes, among others, drugs. Thus we wanted to examine whether in this patient the development of CIPO is related to the treatment with buserelin.

Methods. The patient was examined using oesophago-gastro-duodenoscopy, esophageal and antroduodenojejunal manometry, gastric emptying tests, and histological analyses and immunohistochemistry on full-thickness biopsies including staining with anti-GnRH antibody. Plasma samples were examined by the standard serological analyses and specifically for the occurrence of anti-GnRH antibodies by ELISA methods.

$\underline{\text { Results. }}$ CIPO was diagnosed based on symptoms (abdominal pain, vomiting and constipation), and the results of the clinical examinations, such as signs of esophageal aperistalsis, delayed gastric emptying and small intestinal bursts. Histological examination revealed a decreased number of myenteric neurons as well as increased neuronal degeneration and an abnormal immune profile. There was a loss of GnRH-containing neurons. The patient had high plasma titres of anti-GnRH antibodies, which occurred on the occasions of the treatment with buserelin.

Conclusion. Our findings suggest that the patient has developed CIPO due to buserelininduced formation of anti-GnRH antibodies destroying GnRH-producing neurons of the myenteric plexus. 


\section{Introduction}

Gastrointestinal motility requires coordination between the intrinsic and extrinsic nervous system, the interstitial Cells of Cajal (ICCs) and smooth muscle cells $(1,2)$. Disturbances in digestive motility can occur as a result of a variety of abnormalities affecting each of these elements (alone or in combination) involved in the physiology of gut motor function (3).

Chronic intestinal pseudo-obstruction (CIPO) is a particularly difficult clinical challenge, characterised by the presence of chronic dysmotility and intestinal dilatation in the absence of mechanical obstruction (4). There are two main forms of CIPO i.e. myopathic, involving the intestinal musculature, and neurogenic, involving the extrinsic innervation of the gut or intrinsic (enteric) nerves and pacemaker cells (ICCs) $(5,6)$.

Here we report on a patient who participated in an in-vitro fertilization programme (IVF) and who, following repeated pre-treatment with buserelin, a synthetic gonadotropin-releasing hormone $(\mathrm{GnRH})$ agonist (7), developed a degenerative neuropathic type of CIPO. The patient developed antibodies against buserelin. Our hypothesis is that these antibodies cross-reacted with endogenous GnRH, destroying GnRH-immunoreactive neurons of the myenteric plexus. To our knowledge, this is the first report demonstrating the presence of GnRH-positive neurons in the human gastrointestinal tract. 


\section{Materials and Methods}

\section{Case report}

A 30 year-old woman had been bilaterally salpingectomized due to ectopic pregnancies in 1991-92, complicated by the rupture of the fallopian tubes, and had therefore developed secondary infertility. Her first IVF attempt took place in December 1992 and she was treated with intra-nasal buserelin (total dose $16 \mathrm{mg}$ ). The attempt was unsuccessful wherefore a second IVF procedure with intra-nasal buserelin (total dose $24 \mathrm{mg}$ ) was initiated in March 1993, but was discontinued after 3 weeks because of excessive uterine bleeding. A third IVF attempt in August 1993 using subcutaneous buserelin (total dose $37.5 \mathrm{mg}$ ) was successful and she delivered a child in May 1994.

Six years later the patient desired another child and she was accepted for a fourth IVF programme using subcutaneous buserelin (total dose $17 \mathrm{mg}$ ). This was initiated in April 2000. However, the treatment was discontinued after 17 days because of nausea. Two weeks later the patient experienced acute onset of chest and abdominal pain combined with dysphagia. These symptoms progressed, together with vomiting, constipation, bloating and extensive belching. To avoid symptoms she reduced her food intake, resulting in weight loss. In spite of discontinuing the treatment, her symptoms remained and she had lost $14 \mathrm{~kg}$ of body weight. She was then referred to us in December 2000 due to nausea and dysphagia.

\section{Clinical investigation}

Esophago-gastro-duodenoscopy (EGD) one month before referral gave normal results. Simultaneous videoradiography of the pharynx (barium swallow) indicated a specific swallowing defect with an initial retention of the bolus, which, after a certain time could pass down gradually. The following esophageal videomanometry demonstrated an impaired motility in which $80 \%$ of the swallowing process lacked propagating peristalsis. Furthermore, the lower esophageal sphincter (LES) was short and had a reduced resting pressure of 8 
mmHg. The opening of the LES was normal. The result of computer tomography (CT) of the thorax and upper abdomen was normal, as were the results of extensive analyses of blood, urine and cerebrospinal fluid. Tick-borne encephalitis (TBE), Borrelia, amyloidosis and myasthenia gravis could be excluded. A consultant rheumatologist excluded collagen-vascular disease by several serological analyses. Autonomic nerve function tests showed an abnormal vasoconstriction [z-score $=2.97$ compared to the normal value $<1.64$ (8)], indicating sympathetic neuropathy.

Ambulatory, 24-h, pH monitoring of the esophagus sphincter indicated mild reflux. As the symptoms intensified she was re-examined by EGD, which showed a mild Helicobacter pylori-induced gastritis, for which eradication treatment was given. Further examination with enterography demonstrated extremely slow passage through both the stomach and small intestine, and intestinal manometry displayed abnormal fasting bursts, which raised the suspicion of CIPO. Gastric emptying scintigraphy performed after ingestion of a meal consisting of egg and bread showed a pronounced gastroparesis. After $70 \mathrm{~min}, 75 \%$ of the content remained in the ventricle (T50 for healthy controls; $40 \pm 28 \mathrm{~min}$ ) (9). A measurement of the gastric emptying by using a transit method showed that after ingestion of porridge, milk and bread, only $30 \%$ of the particles were emptied after $8 \mathrm{~h}$ (ref. value for complete emptying: 1.3-5.6 h) (10). A succeeding diagnostic laparoscopy showed no macroscopic pathology of the small intestine, but a markedly reduced peristalsis was noted. There were no signs of endometriosis, adhesions, Meckel's diverticulum or tumours. A diamond shaped, full- thickness wall biopsy was taken one metre proximal to the ileocecal valve and was immediately transported in wet compress for pathological examination.

The follow-up period is now 5 years. The dysphagia is unaltered and the patient is incapable of full time work due to abdominal pain, vomiting and nutritional problems. The patient is currently being considered for an implantation of an electric, gastric stimulator. 


\section{Histopathology}

The biopsy was a piece of full-thickness small intestinal wall, $1.5 \times 1.0 \mathrm{~cm}$ in size. Following fixation overnight in $4 \%$ formalin at room temperature two transverse, fullthickness slices perpendicular to each other were cut and embedded in paraffin for conventional transversal sections. The remaining, larger part of the biopsy was embedded in toto for tangential sectioning, which makes it possible to examine the whole myenteric plexus.

H\&E-stained and transversally cut sections were used in order to determine the number of neurons/mm myenteric plexus. All nerve cells containing nuclei and large, unequivocal neuron-bodies without nuclei were counted. Small, suspected neuroncytoplasmic structures were disregarded. The damaged myenteric neurons were counted in both transversal and tangential sections, and were presented as a percentage of the total number of neurons.

Serial sections from all the three blocks were stained according to a protocol for CIPO analysis, which includes different antibodies for neural tissue and smooth muscle cell staining (11). The specific immunohistochemical stainings were applied for the analysis of neurons (protein gene product 9.5 (PGP 9.5), neurofilaments, synaptophysin, bcl-2, substance $\mathrm{P}$, neuron-specific endolase (NSE) and $\alpha$-internexin), glial cells and Schwann cells (S100), Tlymphocytes (CD3), intermediate/microfilaments of the smooth muscle cells ( $\alpha$-actin, desmin, vimentin) and the interstitial Cajal-cells (ICCs) (CD117 and CD34). For the negative controls, the specific antibody was replaced by non-immunized serum.

The amount of abnormally stained/negative neurons for PGP9.5 and bcl-2 was determined on tangential sections and is given as the percentage of the total neuron population in these sections. 
In addition, the sections were stained with anti-GnRH antibody (anti-LH-RH; PROGEN Biotechnik GmbH, Heidelberg, Germany) at 1:100 dilution, following microwave pre-treatment. The transverse sections were used to determine the amount of GnRH-positive neurons because tangentially cut sections were no longer available. The sections of normal small intestinal tissue from 4 cases of bowel resection due to intestinal carcinomas were used as controls, and were stained as described above.

\section{Assay of human antibodies against GnRH}

Serum samples subjected to various microbiological analyses are routinely stored at $-40{ }^{\circ} \mathrm{C}$ at the Department of Microbiology. A search through her register gave us the possibility to obtain patient serum samples from various years. After the patient had been informed and had given her written consent, the samples were collected and analysed.

Analysis of anti-GnRH antibodies was carried out by an ELISA method. The wells of microtiter plates were coated with human GnRH (Sigma, St Louis, USA) and the plastic wells were blocked with fish gel solution. Serial dilutions of patient serum or (to construct the standard curve) polyclonal rabbit anti-human GnRH antibody (anti-LH-RH; PROGEN Biotechnik GmbH, Heidelberg, Germany) was then added. Bound primary antibodies were detected by peroxidase-conjugated secondary antibody [rabbit anti-human IgA, IgG, IgM antibody or pig anti-rabbit Ig antibody (Sigma)]. The substrate used was 2,2'azino-di(3-ethylbenzthiazoline sulfonic acid) (ABTS, Sigma). The absorbance at $405 \mathrm{~nm}$ $\left(\mathrm{A}_{405}\right)$ was measured in a Titertek Multiscan. Serum from 20 healthy, age matched individuals served as controls. In addition, serum samples from seven females, treated for four weeks with nasal buserelin (total dose of $24 \mathrm{mg}$ ), who had not developed gastrointestinal symptoms, were analyzed for the presence of GnRH antibodies by the ELISA method. 
The assay was carried out as described above except that, after addition of patient serum, a fixed volume of either physiologic saline or buserelin $(0.2 \mathrm{mg} / \mathrm{mL})$ was added.

\section{Statistical methods}

Values are expressed as mean $\pm \mathrm{SD}$. The linearity of the standard curve was estimated by linear regression analysis. The significances of the differences in the proportions of neurons between the patient and the controls were obtained using Pearson's chi-squared test. All calculated $\mathrm{P}$ values were two-sided. 


\section{Results}

\section{Histopathological examination}

The total number of myenteric neurons was significantly lower in the patient compared to the controls: 5.9 vs 16.9 neurons $/ \mathrm{mm}$ length of myenteric plexus $(\mathrm{p}<0.01)$. Twenty percent of the neurons (49 out of 248) of the myenteric plexus in the patient were either swollen, rounded with a smooth surface with or without vacuolation of the cytoplasm, or were shrunken with pyknotic nuclei and amphophilic cytoplasm (Figure 1A). The nerve fibres within the muscle layers were thickened and vacuolated. Swollen/vacuolated or shrunken neurons were not observed in the control material.

The damaged neurons also showed an abnormal immunoprofile. Twenty percent of the neurons (15 out of 75 ) were negative or very weakly stained for protein gene product (PGP9.5) (Fig 1B) and 13\% (12 out of 97) for bcl-2. In contrast, in the control material, all neurons were positive for the PGP9.5 and bcl-2. The swollen neurons in the patient showed very strong and diffuse staining for neurofilament and alpha-internexin. The synaptophysinpattern of the degenerating neurons was also abnormal: the neurons were negative and the continuous pericellular layer of strongly positive small vesicles and granules was disrupted or missing. The immunostaining for substance P and NSE was diminished (data not shown). The number of ICCs was markedly increased within the circular muscle with many, quite large, hypertrophic cells. Several ICCs, both within the intermyenteric/periganglional and in the circular muscle, contained vacuoles in the cytoplasm (Figure 2A and B).

Inflammatory cells were not present around or between the neural structures of the intestinal wall. The amount of myenteric ganglion-related T-cells was $0.35 \pm 0.78$ $($ mean \pm SD) whereas normal values are considered to be $0.17 \pm 0.65$ (11). The mucosa, submucosa, and the smooth muscle cells showed no pathological alterations (data not shown). 
The number of GnRH-positive neurons was dramatically lower in the patient than in the controls $(0.18$ vs $8.64 \mathrm{GnRH}$ positive neurons/mm myenteric plexus, respectively, $p<0.0$ ???) (Figs $3 \mathrm{~A}$ and B). Fifty-three percent of the neurons in the intestinal samples of the controls were moderately or strongly immunopositive in the cytoplasm as shown by the staining with anti-GnRH antibody, whereas only $3 \%$ of the total amount of neurons in the patient showed positive staining $\left[\chi^{2}(1)=58.04, \mathrm{p}<0.001\right]$.

\section{Human antibodies against GnRH}

Linear regression analysis showed a significant correlation between rabbit antihuman GnRH antibody dilutions (1:800-1:51200, corresponding to 1250-20 pg of antibody/well $)$ and $\mathrm{A}_{405}(\mathrm{r}=0.99, \mathrm{p}<0.001)$. Figure 4 shows the time relation between patient serum anti-GnRH antibody titers and the various buserelin treatments of the patient. The competitive binding assay showed that by adding $10 \mu \mathrm{g}$ of buserelin to patient serum (patient sample November 15, 2000 diluted 1:400- 1:3200), the binding of patient anti-GnRH antibody to the solid phase was reduced by $23-39 \%$ compared to that obtained when physiologic saline alone had been added. No antibodies were demonstrated in the controls $(n=20)$ nor in the patients treated with buserelin $(n=7)$ without development of gastrointestinal complaints. 


\section{Discussion}

Due to the clinical picture and the findings of antroduodenojejunal manometry and histopathological analysis, the patient fulfils the criteria for CIPO (12-14). The sudden onset of this disease in a previously seemingly healthy young woman puzzled us. The study of her gynaecology files, revealing her considerable obstetrical history, led us to predict that the treatment with buserelin, a GnRH analogue, might be related to her symptoms. The prediction was further strengthened when it was found that GnRH and GnRH receptor mRNA is present in parasympathetic ganglion cells of the myenteric plexus in rats $(15,16)$.

Chronic intestinal pseudo-obstruction is a disease with many different etiological factors, of which drugs may be one $(5,6)$. A drug-induced immunologic reaction with the formation of cross-reacting antibodies against endogenous $\mathrm{GnRH}$ was postulated. However, radioimmunoassays (RIAs) using either ${ }^{125} \mathrm{I}$-buserelin or ${ }^{125} \mathrm{I}-\mathrm{GnRH}$ (iodinated by the chloramine-T-method) failed to detect antibodies (personal communication, 17). This encouraged us to develop the described ELISA method, which shows that the patient had developed antibodies against buserelin which cross-reacted with endogenous GnRH. Repeated subcutaneous administration of the drug might have induced an immunologic response. The patient was most likely primarily immunized in 1993 and, 6-7 years later, in 2000, when she was treated again with buserelin, she developed a secondary IgG response. As illustrated in Figure 4, the various titers of the antibodies correlate in time with the buserelin treatments. The failure to detect antibodies by the RIAs is unclear; the iodination of the single tyrosine residue in GnRH or buserelin, using the chloramine-T-method, might modify the antibody binding epitope making it unrecognizable to the antibodies.

The intestinal biopsy, taken two years after symptom onset, revealed no signs of inflammation but instead degeneration of the myenteric neurons, combined with hyperplasia of the ICCs of within the circular muscle, and vacuolisation of ICCs in both the 
intermyenteric/periganglional and in the circular muscle. Moreover, as illustrated in Fig 3A and $\mathrm{B}$ the patient had, in contrast to the controls, an almost total absence of GnRH immunoreactive neurons in the small intestine.

In rats, GnRH mRNA has been found in parietal cells of gastric glands, the epithelium of the small and large intestine, and in parasympathetic ganglion cells of the myenteric plexus. In addition, the GnRH receptor has been found in the epithelium of gastric pits (15) and GnRH receptor mRNA in the myenteric neurons in the rat (16). GnRH has also been detected in rat pancreas (18). In dog, GnRH has been shown to inhibit the release of gastric secretions and gastrin release (19), possibly due to diminished vagal activity. To our knowledge, this is the first study revealing the presence of GnRH-positive neurons in the human gastrointestinal tract.

Substitutions in position 6 and 10 of GnRH (pGlu-His-Trp-Ser-Tyr-Gly-LeuArg-Pro-GlyNH ${ }_{2}$ ) lead to greater biological activity and increased half-time (20). Buserelin (pGlu-His-Trp-Ser-Tyr-DSer[0'bu]-Arg-Pro-EtNH ${ }_{2}$ ) is an example of such modifications, another is leuprolide (pGlu-His-Trp-Ser-Tyr-DLeu-Arg-Pro-EtNH $\mathrm{N}_{2}$ ), which has been shown to stimulate intestinal motor activity in rats $(21,22)$. Symptom resolution and alleviation of intestinal motility abnormality after treatment with leuprolide have been reported in a patient with CIPO (23) and patients suffering from irritable bowel syndrome (IBS) (24-26). According to the Swedish Medical Agency one case of intestinal pseudo-obstruction after buserelin treatment has previously been described. The patient recovered uneventfully after cessation of the drug (27).

Although we could not show a direct link between the antibody development against GnRH and the degeneration of the myenteric neurons, the presence of cytomorphologically and immunohistochemically abnormal nerve cells and the reduction of GnRH-positive neurons support the existence of a causal relationship. The interpretation of 
the changes of the ICCs is more difficult because no GnRH-positive ICCs can be found in normal intestine. Taken together, anamnestic and clinical data as well as the microscopic and laboratory findings in our patient indicate that GnRH plays a pivotal role not only in the regulation of different hormones, but also in the regulation of motor activity of the gastrointestinal tract. Destruction of GnRH neurons might be of central importance for the pathophysiology of different forms of CIPO and IBS.

The indication for treatment with buserelin and other long-acting GnRH analogues (leuprolide, triptorelin, hirsterlin, nafarelin and goserelin) includes, apart from IVF, also endometriosis, polycystic ovary syndrome, prostate cancer, uterine leiomyoma and precocious puberty. Gastrointestinal side effects are considered infrequent (28) but nausea and abdominal pain have been reported in 7-17 \% of women treated with buserelin for endometriosis and uterine leiomyoma $(27,29)$. In the majority of these patients the gastrointestinal side effects are most likely due to GnRH-induced disturbed motor activity and not antibody development.

In summary, we report a case of CIPO after buserelin treatment for infertility. The finding of antibodies against $\mathrm{GnRH}$, together with the markedly decreased number of enteric GnRH immunoreactive neurons, offers a basis for the hypothesis that the patient has developed CIPO due to buserelin-induced formation of anti-GnRH antibodies destroying GnRH-producing neurons of the myenteric plexus. Studies in larger groups of patients are needed to prove our hypothesis. Moreover, the physiological and pathophysiological role of GnRH on gastrointestinal functions deserves further study. 


\section{References}

1. Goyal RK, Hirano I. The enteric nervous system. N Engl J Med 1996;334:1106-1115.

2. Wood JD. Neuropathy in the brain-in-gut. Eur J Gastroenterol Hepatol 2000;12:597-600.

3. McCallum RW, Champion MC eds. Gastroinestinal motility disorders. Baltimore, Williams \& Wilkins 1990 .

4. De Giorgio R, Sarnelli G, Corinaldesi R, Stanghellini V. Advances in our understanding of the pathology of chronic intestinal pseudo-obstruction. Gut 2004;53:1549-1552.

5. Patel R, Christensen J. Chronic intestinal pseudo-obstruction: Diagnosis and treatment. The Gastroenterologist 1995;3:345-356.

6. Hirano I, Pandolfino J. Chronic intestinal pseudo-obstruction. Dig Dis 2000;18:83-92.

7. Chengalvala MV, Pelletier JC, Kopf GS. GnRH agonists and antagonists in cancer therapy. Curr Med Chem Anti-Canc Agents 2003;3:399-410.

8. Freccero C, Svensson H, Bornmyr S, Wollmer P, Sundkvist G. Sympathetic and parasympathetic neuropathy are frequent in both type 1 and type 2 diabetic patients. Diabetes Care 2004;27:2936-2941.

9. Hanson M, Lilja B: Gastric emptying in smokers. Scand J Gastroenterol 1987;22 : 1102-1104.

10. Sadik R, Abrahamsson H, Stotzer P-O. Gender differences in gut transit shown with a newly developed radiological procedure. Scand J Gastroenterol 2003;38:36-42.

11. Törnblom H, Lindberg G, Nyberg B, Veress B. Full-thickness biopsy of the jejunum reveals inflammation and enteric neuropathy in irritable bowel syndrome.

Gastroenterology 2002;123:1972-1979.

12. Stanghellini V, Camilleri M, Malagedala J-R. Chronic idiopathic intestinal pseudoobstruction: clinical and intestinal manometric findings. Gut 1987;28:5-12.

13. Mann SD, Debinski HS, Kamm MA. Clinical characteristics of chronic idiopathic 
intestinal pseudo-obstruction in adults. Gut 1997;41:675-681.

14. De Giorgio R, Camilleri M. Human enteric neuropathies: morphology and molecular pathology. Neurogastroenterol Motil 2004;16:515-531.

15. Huang W, Yao B, Sun L, Pu R, Wang L, Zhang R. Immunohistochemical and in situ hybridization studies of gonadotropin releasing hormone $(\mathrm{GnRH})$ and its receptor in rat digestive tract. Life Sci 2001;68:1727-1734.

16. Ho JS, Nagle GT, Mathias JR, Clench MH, Fan X, Kalmaz GD, Sallustio JE, Eaker EY. Presence of gonadotropin-releasing hormone $(\mathrm{GnRH})$ receptor mRNA in rat myenteric plexus cells. Comp Biochem Physiol 1996;113:817-821.

17. Sandow J. Aventis Pharma, Hoecht Industry Park, Frankfurt am Main, Germany.

18. Wang L, Xie LP, Huang WQ, Yao B, Pu RL, Zhang RQ. Presence of gonadotropinreleasing hormone $(\mathrm{GnRH})$ and its mRNA in rat pancreas. Mol Cell Endocrinol 2001;14:172185.

19. Soldani G, Del Tacca M, Bambini G, Polloni A, Bernardini C, Martinotti E, Martino E. Effects of gonadotropin-releasing hormone $(\mathrm{GnRH})$ on gastric secretion and gastrin release in the dog. J Endocrinol Invest 1982;5:393-396.

20. Schally AV. Luteinizing hormone-releasing hormone analogs: their impact on the control of tumorigenesis. Peptides 1999:20:1247-1262.

21. Khanna R, Browne RM, Heiner AD, Clench MH, Mathias JR. Leuprolide acetate affects intestinal motility in female rats before and after ovariectomy. Am J Physiol 1992;262:G185G190.

22. Ducker TE, Boss JW, Altug SA, Mehrabian H, Dekeratry DR, Clench MH, Mathias JR. Luteinizing hormone and human chorionic gonadotropin fragment the migrating myoelectrical complex in rat small intestine. Neurogastroenterol Motil 1996;8:95-100. 
23. Mathias JR, Baskin GS, Reeves-Darby VG, Clench MH, Smith LL, Calhoon JH. Chronic intestinal pseudoobstruction in a patient with heart-lung transplant. Therapeutic effect of leuprolide acetate. Dig Dis Sci 1992;37:1761-1768.

24. Mathias JR, Clench MH, Reeves-Darby VG, Mehelich Fox L, Hsu PH, Roberts PH, Smith LL, Stiglich NJ. Effect of leuprolide acetate in patients with moderate to severe functional bowel disease. Dig Dis Sci 1994;39:1155-1162.

25. Mathias JR, Clench MH, Abell TL, Koch KL, Lehman G, Robinson M, Rothstein R, Snape WJ. Effect of leuprolide acetate in treatment of abdominal pain and nausea in premenopausal women with functional bowel disease: a double-blind, placebo-controlled, randomized study. Dig Dis Sci 1998;43:1347-1355.

26. Palomba S, Orio F, Manguso F, Russo T, Falbo A, Lombardi G, Doldo P, Zullo F. Leuprolide acetate treatment with and without coadministration of tibolone in premenopausal women with menstrual cycle-related irritable bowel syndrome. Fertility and Sterility $2005 ; 83: 1012-1020$.

27. WHO's registration of side effects.

28. FASS $^{\mathrm{R}}$, the Swedish register of drugs.

29. Micromedex, Drugdex, Drug Evaluation. 

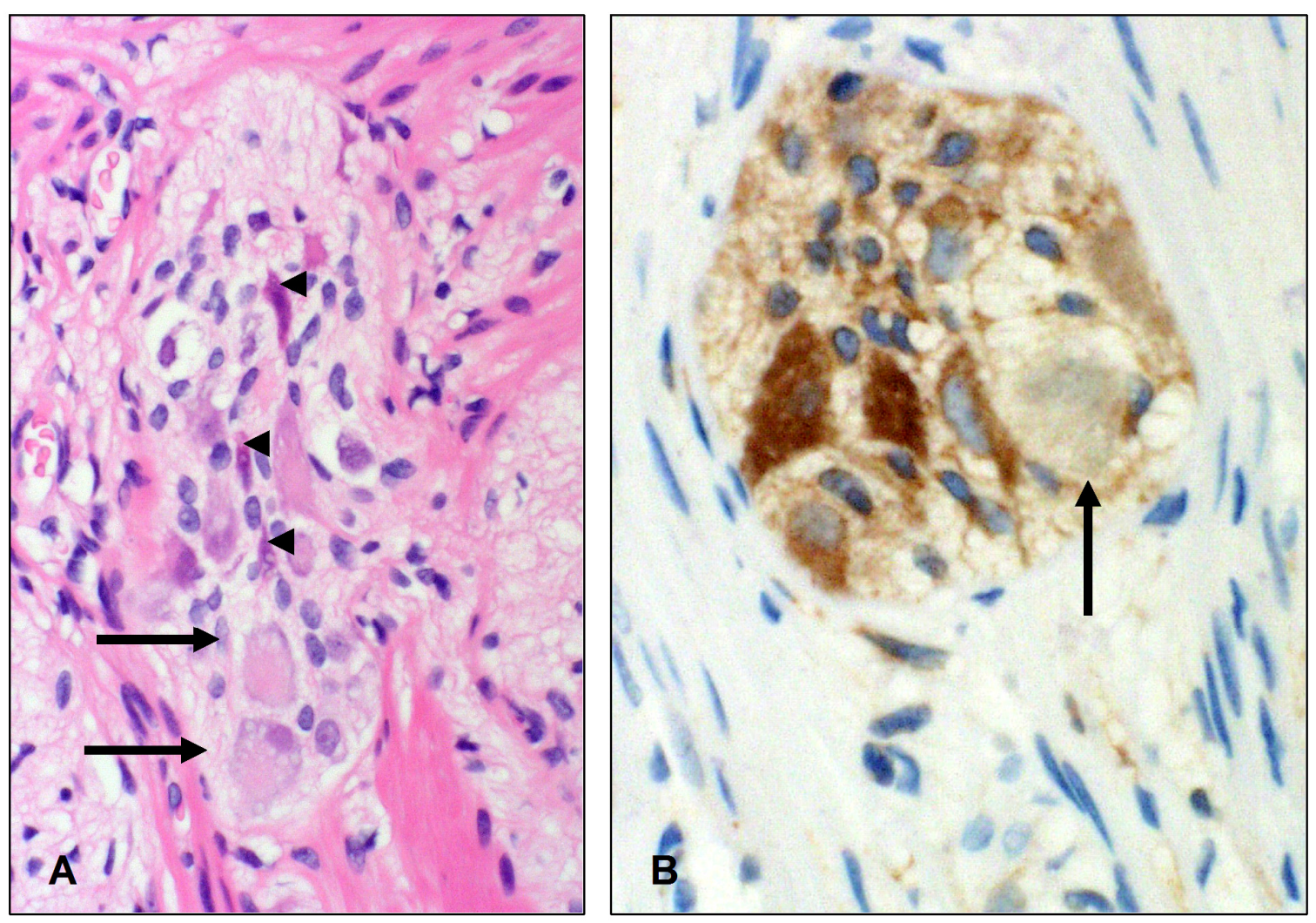

Figure 1
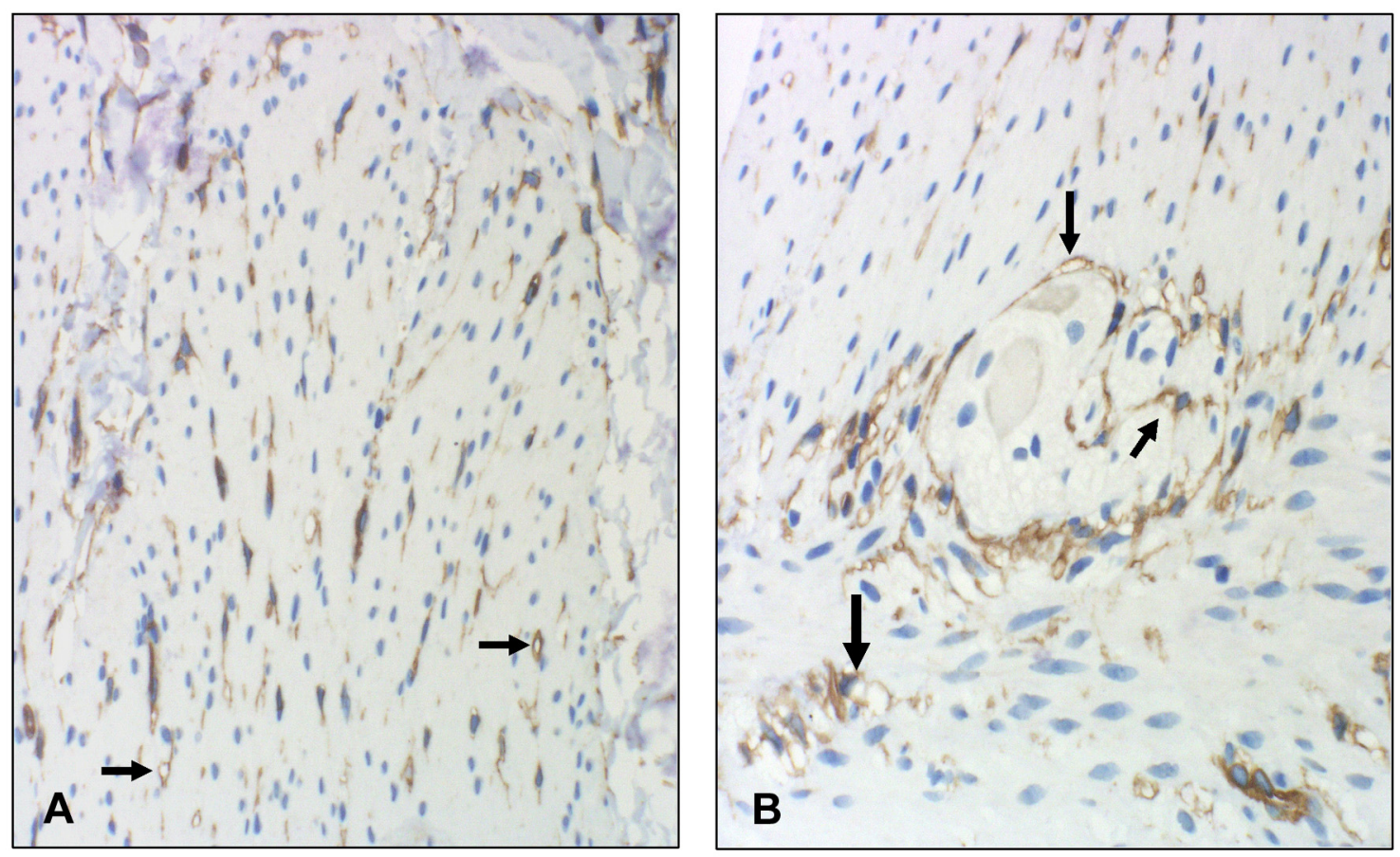

Figure 2 

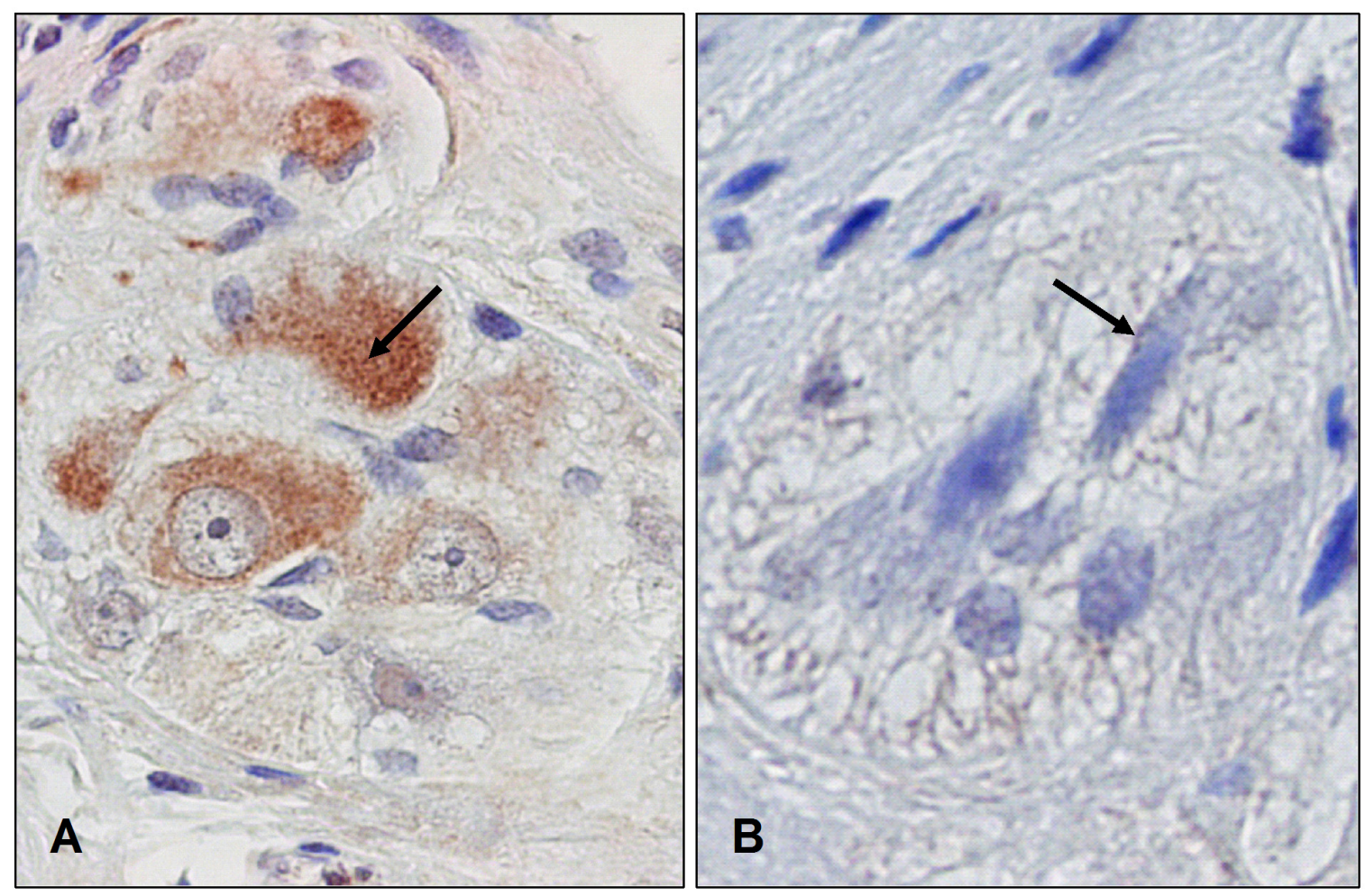

Figure 3

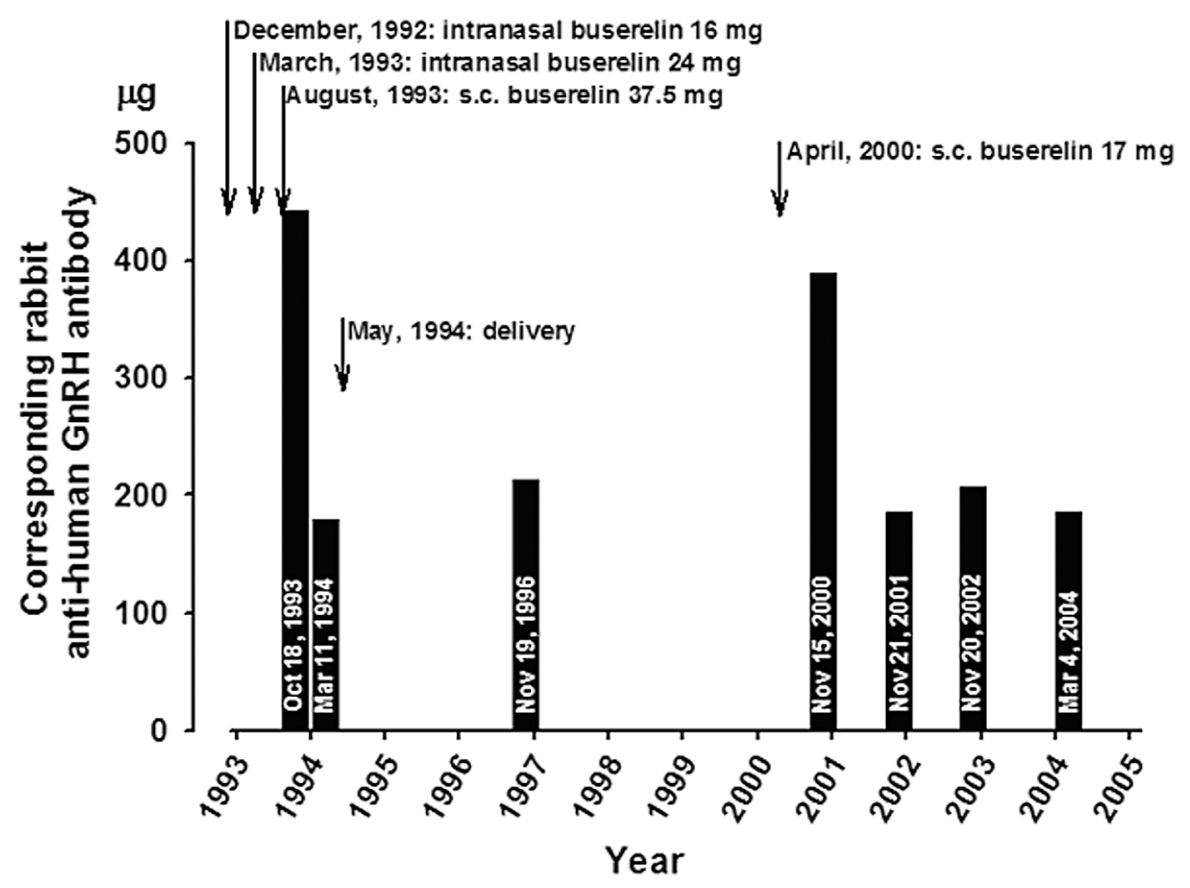

Figure 4 